\title{
Sağlıkta Şiddet Bir İş Güvenliği Sorunu mudur: Sakarya’da Görev Yapan Bir Grup Sağlık Çalışanının Sağlıkta Şiddet ile İlgili Görüşlerinin Değerlendirilmesi
}

Is Violence in Health a Occupational Safety Problem: Evaluation of the Opinions of a Group of Health Workers in Sakarya on Violence in Health

\author{
Fulya Aktan Kibar ${ }^{1}$, Gökhan Oturak ${ }^{1}$, Hasan Çetin Ekerbiçer ${ }^{1}$, Ufuk Berberoğlu ${ }^{2}$ \\ ${ }^{1}$ Sakarya Üniversitesi Tip Fakültesi Halk Sağlı̆̆ı Anabilim Dalı, Sakarya \\ ${ }^{2}$ Uşak Üniversitesi Tip Fakültesi Halk Sağglğg Anabilim Dalı, Uşak \\ Yazışma Adresi / Correspondence: \\ Gökhan Oturak \\ Sakarya Üniversitesi Tip Fakültesi Halk Sağlığı Anabilim Dalı, Sakarya \\ T: +90536 6481378 E-mail : g.oturak@gmail.com
}

Geliş Tarihi / Received : 07.08.2019 Kabul Tarihi / Accepted : 10.10.2019

Orcid :

Fulya Aktan Kibar https://orcid.org/: 0000-0003-3080-4280

Gökhan Oturak https://orcid.org/0000-0003-1608-8433

Hasan Çetin Ekerbiçer https://orcid.org/0000-0003-0064-3893

Ufuk Berberoğlu https://orcid.org/0000-0002-4088-7289

( Sakarya Tip Dergisi / Sakarya Med J 2019, 9(4):612-618) DoI: 10.31832/smj.603429

\footnotetext{
$\ddot{0} z$

Amaç İs yerinde șiddete maruz kalan meslek gruplarının başında sağlık çalıșanları gelmektedir. Sağlık çalıșanlarına yönelik șiddeti önlemek ancak sağlıkta șiddetin nedenlerinin detaylı bir şekilde incelenmesi sonucu gerçekleşebilir. Bu çalışmada, Sakaryảdaki sağlık çalışanlarının bakış açısıyla sağlık çalışanlarına yönelik şiddetin en önemli nedenlerinin ve sağlık çalışanlarının sağlık personeline yönelik şiddeti bir iş güvenliği sorunu olarak görüp görmediklerinin incelenmesi amaçlanmıştır.

Gereç ve Araștırmaya Sakaryảdaki bazı aile sağlığı merkezlerinden ve Sakarya Eğitim ve Araștırma Hastanesỉnden toplam 187 sağlık çalıșanı katılmıștır. Tanımlayııı tipteki Yöntemler bu araștırma, araștırmacılar tarafından hazırlanan sekiz sorudan olușan anket formu ile veri toplanarak 4 Mayıs - 31 Mayıs 2019 tarihleri arasında yürütülmüștür. Üç katılımcının anket formunda eksik veriler olduğundan çalışmada 184 kişinin anketi değerlendirmeye alınmıştır. Tanımlayıcı istatistikler, sayı ve yüzde olarak ifade katılımcinșị.

Bulgular Araştırmaya katılan 184 katılımcıdan 18’i (\%9,78) “Son 12 ayda bir iş kazasına uğradığınız mı?” sorusuna "Evet" cevabını vermiştir. Katılımcıların 103’ü (\%55,98) son 12 ay içinde sözlü ve/veya fiziksel șiddete uğradığını belirtmiștir. Katılımclar, sağlık personeline yönelik șiddetin en önemli sebebi olarak en sık; toplumun genelinde sosyokültürel düzeyin düșük olmasından kaynaklanan, hastaların olumsuz tavır ve davranıșları $(\% 27,01)$ cevabını vermiștir.

Sonuç Araștırmaya katılan sağlık çalıșanlarının büyük coğunluğu, sağlık personeline yönelik fiziksel ve/veya sözlü șiddeti is kazası olarak değerlendirmemektedir. Sağlık çalıșanlarının büyük bir kısmı sağlık personeline yönelik şiddetin en önemli sebebinin hasta/hasta yakını kaynaklı ve sağlık sistemi ile alakalı sorunlar olduğunu belirtirken, katılımcıların çok az bir kısmı sağlıkta şiddetin sağlık çalışanları kaynaklı olduğunu düşünmektedir.

Anahtar sağlık çalışanları; iş yerinde şiddet; iş kazası

Abstract

Objective Health workers are the leading occupational groups exposed to violence in the workplace. Preventing violence against healthcare workers can only be achieved by elaborating the causes of violence in health. In this study, it was aimed to examine the most important reasons of violence against health workers from the perspective of health workers in Sakarya and whether health workers see violence against health personnel as an occupational safety problem.

Materials

This descriptive study was conducted between May 4 and May 31, 2019 by a questionnaire prepared by the researchers. The study was completed with 184 people because there was missing data in the questionnaire form of the three participants. Descriptive statistics were expressed as numbers and percentages.

Results 18 of the 184 participants (9.78\%) answered "Yes" to the question "Have you had an occupational accident in the last 12 months?". 103 (55.98\%) of the participants stated that they have been subjected to verbal and / or physical violence in the last 12 months. Participants most frequently answered the negative attitudes and behaviors of the patients due to the low socio-cultural level in the general population (27.01\%) as the most important cause of violence against health personnel.

Conclusion The majority of the health workers participating in the study do not consider physical and / or verbal violence against health personnel as occupational accidents. While health workers state that the most important reason of violence against health personnel is patient / patient relative and health system related problems, very few of the participants think that health violence is caused by health workers.

Key words medical staffs; workplace violence; occupational accident
} 


\section{GIIRIŞ}

"İşyerinde şiddet" sağlık çalışanları için dünya çapında bir sorundur. "İşyerinde şiddet”, Ulusal Mesleki Güvenlik ve Sağlık Enstitüsü (National Institute for Occupational Safety and Health-NIOSH) tarafından, işte ya da görevde olan bir kişiye yönelik fiziksel saldırıları da içeren tüm şiddet eylemleri olarak tanımlanmıştır. ${ }^{1}$ Devlet ve özel sektörde hastaneler, diğer sektörlere kıyasla dört kat daha fazla şiddete bağlı yaralanma oranlarına sahiptir. ${ }^{2}$

İşyerinde şiddete maruz kalmanın; çalışanlarda hem kurumsal hem de bireysel düzeyde tükenmişlik algılarını arttırma, iş performansını ve iş tatminini azaltma, düşmanca bir çalışma ortamı yaratma ve hastalara yetersiz düzeyde bakım verme gibi birçok olumsuz etkisi vardır. ${ }^{1}$ İşyerinde şiddete maruz kalmak, çalışanların sağlık şikâyetlerinde artışa yol açmaktadır. Sözlü veya fiziksel şiddete uğrayan çalışanlarda; irritabilite, karın ağrısı, kaygı ve uyku bozuklukları gibi sağlık problemlerinin gelişme ihtimali diğer çalışanlardan dört kat fazladır. ${ }^{3}$

Dünya Sağlık Örgütünün verilerine göre sağlık çalışanlarının \%8 ila \%38'i kariyerlerinde bir noktada fiziksel şiddete maruz kalmakta iken, çok daha fazlası ise tehdit veya sözlü şiddete maruz kalmaktadır. ${ }^{4}$ Türkiye'de sağlık çalışanlarının fiziksel şiddete maruz kalma sıklığı $\% 1,80$ ile \%52,50 arasında değişirken sözel şiddete maruz kalma sıklığı ise $\% 46,70$ ile $\% 100$ arasında değiş̧mektedir. ${ }^{5}$

1998'de ILO (International Labour Organization - Uluslararası Çalışma Örgütü) tarafından gerçekleştirilen 16. ICLS (International Conference of Labour Statisticians - Uluslararası Çalışma İstatistikçileri Toplantısı)'den beri şiddet olayları dünya literatüründe iş kazası olarak değerlendirilmektedir. Bu çerçevede iş kazası tanımı da "Bir veya daha fazla çalışanın yaralanması, hastalanması veya ölümü ile sonuçlanan; plansız bir şekilde ortaya çıan, şiddet olaylarını da içerisine alan işten kaynaklanan veya iş ile bağlantılı olarak ortaya çıkan durum" olarak tanımlanmıştır. ${ }^{6}$
Ayrıca Amerika Birleşik Devletleri Çalışma Bakanlığı’nın 1970 tarihli İş Sağlığı ve Güvenliği Yasası̉na (Occupational Safety and Health Act of 1970) dayanarak 2016 yllında yayınladığı “Sağlık ve Sosyal Hizmet Çalışanları için İşyerìnde Şiddetten Korunma Rehberi”nde iş yerindeki şiddetin yasa kapmasında değerlendirildiği, gerekli önlemlerin ve bildirimlerin yapılmaması durumunda işverenin cezalandırılacağı açıkça belirtilmektedir.?

Sağlık çalışanlarının maruz kaldığı şiddet oranları bu kadar yüksek olduğu halde, ülkemizde sağlık çalışanlarını şiddetten koruyacak sınırlı sayıda kontrol mekanizması mevcuttur. Ülkemizde sağlıkta kalite çalışmaları kapsamında; sağlık çalışanlarına yönelik şiddet riski/girişimi varlığında ya da şiddet uygulanması halinde, olaya en kısa sürede müdahalenin yapılması amaciyla 2011 yılında beyaz kod uygulaması başlatılmıştır. Beyaz kod uygulaması yolu ile en yakın sabit hattan 1111 tuşlanarak güvenlik güçlerinin olay mahalline en kısa sürede iştiraki sağlanır. 11 Kasım 2011 tarihinde yürürlüğe giren 663 sayılı Sağlık Bakanlığı ve Bağlı Kuruluşlarının Teşkilat ve Görevleri Hakkında Kanun Hükmünde Kararname kapsamında sağlık çalışanlarına hukuki yardım verilmesi konusunda kanuni bir düzenleme yapılmıştır. Bu maddeye dayanılarak Bakanlık ve bağlı kuruluşlarınca yapılacak hukuki yardıma ilişkin usul ve esasları belirlemek amacıyla "Sağlık Bakanlığı Personeline Karşı İşlenen Suçlar Nedeniyle Yapılacak Hukuki Yardım Usul ve Esasları Hakkında Yönetmelik" 28/04/2012 tarihinde Resmi Gazetede yayınlamıştır. Sağlık bakanlığının tüm sağlık çalışanları şiddete maruz kaldıkları durumlarda, bu düzenlemeler doğrultusunda, bakanlık avukatları tarafından beyaz kod uygulaması ile gerekli hukuki yardımı alabilmektedir. ${ }^{9-10}$ Bu düzenlemelere ek olarak 2016 yılında sağlık bakanlığı tarafından yayınlanan genelge ile özel sağlık kuruluşlarında çalışan personel de göreviyle bağlantılı olarak kendisine karşı işlenen suçlar bakımından Türk Ceza Kanununun uygulanmasında kamu görevlisi sayılmaya başlanmıştır. Ve mağdurun talebi halinde ifadesinin görev yaptığı yerde alınabilmesi mümkün olmuştur. ${ }^{11}$ 
Bununla birlikte ülkemizde de iş sağlığı ve güvenliği mevzuatı iş yerinde şiddeti ve sonuçlarını yönetebilecek yeterliliktedir. Gerek 5510 sayılı Sosyal Sigortalar ve Genel Sağlık Sigortası kanununda gerek 6331 sayılı İş Sağlığı ve Güvenliği kanununda yer alan iş kazası tanımı, dünyadaki örneklerine benzer şekilde iş yerinde maruz kalınan şiddet ve sonuçlarını da kapsamaktadır. İş Sağlığı ve Güvenliği kanununa göre iş kazası; "iş yerinde veya işin yürütümü nedeniyle meydana gelen, ölüme sebebiyet veren veya vücut bütünlüğünü ruhen ya da bedenen özre uğratan olay” olarak tanımlanmıştır. Ayrıca kaza öncesi ve sonrası işverenin yükümlülükleri de bu kanunda açıkça belirtilmiştir. $^{12-13}$

Sağlık çalışanlarına yönelik şiddet, hem sağlık personelini hem de sağlık hizmetinin kalitesini etkilemesi ve duraksatması nedeniyle sağlık hizmetinden yararlanan toplumu olumsuz yönde etkileyen bir halk sağlığı sorunudur. Sağlık çalışanlarına yönelik şiddeti önlemek için, öncelikle altta yatan nedenlerin ortaya çıkarılması gerekmektedir. Sağlıkta şiddet, bire bir neden sonuç ilişkisi kurmanın güç olduguu, çok faktörlü bir sorundur. Sağlık hizmeti alanların yaklaşımı kadar işveren ve sağlık çalışanlarının algısı ve bakış açıları da önemlidir. Bu çalışmada, Sakarya'da görev yapan bir grup sağlık çalışanının sağlıkta şiddetin nedenleri ile ilgili görüşlerini ve bu olaya bir iş güveliği sorunu olarak bakıp bakmadıklarını öğrenmek amaçlanmıştır.

\section{GEREÇ ve YÖNTEMLER}

Tanımlayıcı tipte tasarlanan bu çalışma, 4 Mayıs - 31 Mayıs 2019 tarihleri arasında Sakaryadaki aile sağlığı merkezleri ile Sakarya Eğitim ve Araştırma Hastanesi’nin araştırmaya katılmayı kabul eden toplam 187 çalışanında yürütülmüştür. Katılımcılardan 3'ünün anket formunda eksik bilgiler olduğundan araştırma dışı bırakılarak çalışma toplam 184 sağlık çalışanı ile tamamlanmıştır.

Katılımcılara araştırmacılar tarafından literatür desteği ile hazırlanan 8 soruluk anket formu, öncesinde sözlü onam alınarak uygulanmıştır. Anket formunun ilk bö- lümünde sosyodemografik bilgilerle alakalı sorular yer almıştır. Araştırmaya katılanların çalıştıkları birimdeki görevleri; doktor, hemşire/ebe, tekniker/teknisyen, tıbbi sekreter, idari personel ve diğer olarak sınıflandırılmıştır. Katılımcılar arasından görevi fizyoterapist, diyetisyen, güvenlik, çaycı, aile sağlığı elemanı, sağlık memuru, temizlik personeli ve sosyal çalışmacı olanlar diğer grubuna dahil edilmiştir. Anketin ikinci bölümünde katılımcıların son 1 yıl içerisinde iş kazasına uğrama durumları ile iş yerinde sözlü ve fiziksel şiddete maruz kalma öyküleri sorgulanmıştır. Sonrasında katılımcılara sağlık çalışanlarının iş kazası kavramına bakış açısını değerlendirmeye yönelik, yedi farklı durum arasından hangilerinin iş kazası olarak değerlendirilebileceği şeklinde bir soru yöneltilmiştir. Son soru olarak ise katılımcılara "Sağlık personeline yönelik şiddetin sizce en önemli sebebi nedir?” sorusu açık uçlu olarak sorulmuştur. Bu soruya katılımcıların verdiği 56 farklı, toplam 348 cevap benzer nedenler gruplandırılarak toplam 15 farklı başlık altında toplanarak değerlendirilmiştir.

Araştırma için Sakarya Üniversitesi Girişimsel Olmayan Etik Kurulundan 03.05.2019 tarihli E.5553 sayılı etik kurul onayı alınmıştır.

Tanımlayıcı istatistikler; sayısal değişkenler için aritmetik ortalama \pm standart sapma (SS), en küçük ve en büyük değerler şeklinde ifade edilmiştir. Kategorik değişkenlerin frekans sayıları (n) ve yüzdeleri (\%) belirtilmiştir. Analizler için SPSS v20.0 (IBM SPSS Statistics for Windows, Version 20.0; Armonk, NY, USA) istatistik paket programı kullanılmıştır.

\section{BULGULAR}

Çalışmaya katılan sağlık çalışanlarının yaş ortalaması $36,43 \pm 9,27$ yıldır (en küçük değer=20, en büyük değer=63). Çalıșmaya katılan 184 katılımcının 118'i $(\% 64,13)$ kadın, 66's1 $(\% 35,87)$ erkek sağlık personelidir. Görev dağılımına göre katılımcılar incelendiğinde; 70'i $(\% 38,04)$ doktor, 66’sı $(\% 35,87)$ hemşire/ebe, 16’sı $(\% 8,70)$ tıbbi sekreter, 
11 'i $(\% 5,98)$ tekniker/teknisyen, altısı $(3,26)$ idari personel ve 15 'i $(\% 8,15)$ diğer çalışanlardan oluşmaktadır (Tablo 1$)$. Çalışmaya katılanların 18'i $(\% 9,78)$ "Son 12 ayda iş kazasına uğradığınız mı?” sorusuna "Evet” yanıtını vermiştir. $\mathrm{Bu} 18$ katılımcının üçü son 12 ay içinde birden fazla iş kazasına uğradığını belirttiği için toplam 21 iş kazası rapor edilmiştir. Yaşanan 21 iş kazasının dağılımı Tablo 2'de gösterilmiştir.

\begin{tabular}{|c|c|c|c|}
\hline \multicolumn{4}{|c|}{$\begin{array}{l}\text { Tablo 1.Araştırmaya katılan sağlık personellerinin yaş, cinsiye } \\
\text { ve görev dağılımları }\end{array}$} \\
\hline \multicolumn{2}{|c|}{ Özellikler } & \multirow{2}{*}{$\begin{array}{c}\text { Sayı (n) } \\
47\end{array}$} & \multirow{2}{*}{$\begin{array}{c}\text { Yüzde (\%) } \\
25,54\end{array}$} \\
\hline \multirow{4}{*}{$\begin{array}{c}\text { Yaş } \\
(\mathrm{n}=184)\end{array}$} & $20-29$ & & \\
\hline & $30-39$ & 63 & 34,24 \\
\hline & $40-49$ & 60 & 32,61 \\
\hline & $\geq 50$ & 14 & 7,61 \\
\hline \multirow{2}{*}{$\begin{array}{l}\text { Cinsiyet } \\
(n=184)\end{array}$} & Kadın & 118 & 64,13 \\
\hline & Erkek & 66 & 35,87 \\
\hline \multirow{6}{*}{$\begin{array}{c}\text { Görevi } \\
(\mathrm{n}=184)\end{array}$} & Doktor & 70 & 38,04 \\
\hline & Hemşire/Ebe & 66 & 35,87 \\
\hline & Tibbi Sekreter & 16 & 8,70 \\
\hline & $\begin{array}{l}\text { Tekniker/ } \\
\text { Teknisyen }\end{array}$ & 11 & 5,98 \\
\hline & İdari Personel & 6 & 3,26 \\
\hline & Diğer & 15 & 8,15 \\
\hline
\end{tabular}

Tablo 2. Son 12 ayda iş kazasına uğradığını belirten sağlık çalışanlarının ifade ettiği iş kazaları

\begin{tabular}{|l|c|c|}
\hline İş kazası türleri & Sayı (n) & Yüzde (\%) \\
\hline Enjektör ucu batması & 13 & 61,90 \\
\hline İlaç ampulünün kırılıp batması & 3 & 14,30 \\
\hline El burkulması & 1 & 4,76 \\
\hline Ayak burkulması & 1 & 4,76 \\
\hline Yanık & 1 & 4,76 \\
\hline Köpek ısırması & 1 & 4,76 \\
\hline Sözlü taciz/hakaret & 1 & 4,76 \\
\hline Toplam & 21 & 100,00 \\
\hline
\end{tabular}

Katılımcıların 103'ü $(\% 55,98)$ son 12 ay içinde sözlü ve/ veya fiziksel şiddete uğradığını belirtmiştir. Sözlü şiddete uğradığını belirtenlerin sayısı $102(\% 55,43)$ iken, fiziksel şiddete uğradığını belirtenlerin sayısı 2'dir(\%1,09). Bir katılımcı ise son 12 ay içinde hem sözlü hem de fiziksel şiddete uğradığını belirtmiştir.

"Son 12 ayda iş yerinizde fiziksel şiddete uğradınız mı?" sorusuna iki kişi "Evet” cevabını vermiştir. Bu iki kişiden biri hasta ve hasta yakını tarafından darp edilmenin iş kazası olarak değerlendirilmesi gerektiğini belirttiği halde "Son 12 ayda iş kazasına uğradınız mı?” sorusuna her iki katılımcı da "Hayır” cevabını vermiştir.

Sağlık çalışanlarına yöneltilen, "Sizce aşağıda belirtilen durumlardan hangilerini iş kazası olarak değerlendirmek uygun olur?” sorusundaki yedi farklı durum için katılımcıların verdiği cevapların dağılımına göre katılımcılar, "işlem esnasında çalışanın eline iğne batması” (\%94,02), “işlem esnasında çalışanın gözüne hastanın vücut sıvılarının sıçraması" (\%90,22), “çalışanın iş yerinde düşüp yaralanması" $(\% 80,43)$ gibi durumlara büyük ölçüde doğru cevaplar vermiştir. Ancak sağlık çalışanları, "çalışanın hasta / hasta yakınları tarafından darp edilmesi" $(\% 63,59)$ ve "çalışanın hasta / hasta yakını tarafından hakarete uğraması" $(\% 48,37)$ gibi iş yerinde fiziksel ve sözlü şiddete uğrama durumlarını daha düşük oranda iş kazası olarak değerlendirmiştir (Tablo 3).

\begin{tabular}{|c|c|c|}
\hline \multicolumn{3}{|c|}{$\begin{array}{l}\text { Tablo 3.Sağlık çalıșanlarının, “Sizce aşağıda belirtilen durumlardan } \\
\text { hangilerini iş kazası olarak değerlendirmek uygun olur?” sorusuna } \\
\text { verdikleri doğru ve yanlıș yanıtların dağılımı }\end{array}$} \\
\hline $\begin{array}{l}\text { İş kazası olarak değerlendirilmesi } \\
\text { uygun olup olmadığı sorulan } \\
\text { durumlar }\end{array}$ & Evet & Yüzde (\%) \\
\hline İşlem esnasında ele iğne batması & $173(94,02)^{*}$ & $11(5,98)$ \\
\hline $\begin{array}{l}\text { İşe gelirken çalışanın kendi aracı ile } \\
\text { kaza geçirmesi }\end{array}$ & $53(28,80)$ & $131(71,20)^{\star}$ \\
\hline $\begin{array}{l}\text { Çalıșanın hasta / hasta yakınları } \\
\text { tarafından darp edilmesi }\end{array}$ & $117(63,59)^{*}$ & $67(36,41)$ \\
\hline $\begin{array}{l}\text { Çalışanın evinde banyo yaparken } \\
\text { kayıp düşmesi }\end{array}$ & $1(0,54)$ & $183(99,46)^{\star}$ \\
\hline $\begin{array}{l}\text { Çalıșanın hasta / hasta yakını } \\
\text { tarafından hakarete uğraması }\end{array}$ & $95(51,63)^{*}$ & $89(48,37)$ \\
\hline $\begin{array}{l}\text { İşlem esnasında çalışanın gözüne, } \\
\text { hastanın vücut sıvılarının sıçraması }\end{array}$ & $166(90,22)^{*}$ & $18(9,78)$ \\
\hline $\begin{array}{l}\text { Çalışanın iş yerinde düşüp yaral- } \\
\text { anması }\end{array}$ & $148(80,43)^{\star}$ & $36(19,57)$ \\
\hline
\end{tabular}


"Sağlık personeline yönelik şiddetin sizce en önemli sebebi nedir?" sorusuna katılımcılar 56 farklı, toplam 348 cevap vermiştir. Bu cevaplardan, benzer nedenler gruplandırılarak toplam 15 farklı başlık altında incelenmiştir. Katılımcılar, sağlık personeline yönelik şiddetin en önemli sebeplerini, "toplumun genelinde sosyokültürel düzeyin düşük olmasından kaynaklanan, hastaların olumsuz tavır ve davranışları" (\%27,01), "hasta/hasta yakını ve sağlı personeli arasındaki karşılıklı iletişim sorunları” (\%15,23) ve “sağlık personeline şiddet uygulayanları cezalandırmaya yönelik yasal düzenlemelerdeki yetersizlikler" $(\% 11,78)$ olarak belirtmişlerdir (Tablo 4).

\begin{tabular}{|c|c|c|}
\hline Sağlık çalışanlarına göre sağlıkta şiddetin nedenleri & Sayı (n) & Yüzde (\%) \\
\hline Toplumun genelinde sosyokültürel düzeyin düşük olmasından kaynaklanan, hastaların olumsuz tavır ve davranışları & 94 & 27,01 \\
\hline Karşılıklı iletişim sorunları & 53 & 15,23 \\
\hline Sağlık personeline şiddet uygulayanları cezalandırmaya yönelik yasal düzenlemelerin yetersizliği & 41 & 11,78 \\
\hline $\begin{array}{l}\text { Sağlık bakanlığının, sağlık çalışanlarının şiddetten korunmasına yönelik gerekli önlem ve tedbirleri almada yetersiz } \\
\text { kalması }\end{array}$ & 24 & 6,90 \\
\hline Sağlık personelinin itibarsızlaştırılması & 23 & 6,61 \\
\hline Sağlık politikaları belirlenirken popülist yaklaşımlarda bulunulması & 23 & 6,61 \\
\hline İş yükünün fazlalığı, yetersiz muayene süreleri, sağlık çalışanlarının sayısının yetersiz olması gibi sağlık sistemi sorunları & 21 & 6,03 \\
\hline Hasta ve hasta yakınlarının sağlık çalışanlarına karşı önyargılı olması & 16 & 4,60 \\
\hline Sosyal medya ve basının şiddeti kışkırtması & 14 & 4,02 \\
\hline Hasta ve hasta yakınlarının yüksek beklentileri & 12 & 3,45 \\
\hline Hasta ve hasta yakınlarının yasal olmayan istekleri & 9 & 2,59 \\
\hline Toplumda şiddet eğiliminde artış & 8 & 2,30 \\
\hline Sağlık çalışanlarının yetersiz iletişim becerilerine sahip olması & 5 & 1,44 \\
\hline Hastaların 2. ve 3. basamak sağlık hizmetlerine kolay ulaşabilmesi & 3 & 0,86 \\
\hline Tükenmişlik sendromu ve depresyon gibi sağlık çalışanlarını etkileyen rahatsızlıklar & 2 & 0,57 \\
\hline Toplam & 348 & 100,0 \\
\hline
\end{tabular}

\section{TARTIŞMA}

Sakarya'daki bazı aile sağlığı merkezi çalışanları ve Sakarya Eğitim ve Araştırma Hastanesi çalışanlarıyla yürütülen bu çalışmada, toplam 184 katılımcının anketleri değerlendirmeye alınmıştır. Sağlık çalışanlarının cinsiyet, yaş ve görev dağılımları incelendiğinde büyük çoğunluğunun kadın, 30 - 39 yaş aralığında ve doktor olduğu görülmüştür. Araştırmaya katılan sağlık personellerinin çoğunun kadın olması literatürdeki diğer çalışmalar ile benzerlik göstermektedir. ${ }^{1,2,14-16}$ Bunun nedeni sağlık hizmet sektöründe kadın istihdamının, erkeklere oranla daha yüksek olmasıdır.

Araştırmaya katılanların 18'i $(\% 9,78)$ son 12 ay içerisinde iş kazası geçirdiklerini belirtirken, en sık geçirilen iş kazasının, enjektör ucu batması olduğu ifade edilmiştir. Literatürde ise iş kazası geçirme sıklığının \%10 ile \%70 arasında değişiklik gösterdiği görülmüştür. ${ }^{17-19} \mathrm{Bu}$ farklılığın sebebi ise mesleklerine göre sağlık personeli dağılımının her araştırmada benzer olmamasından kaynaklanmaktadır. Mevcut araştırmada hem hekim ve hemşire dışı sağlık personeli sayısının diğer araştırmalara göre fazla olması hem de mevcut hekim ve hemşirelerin önemli bir kısmının, hastanelere göre çok daha az girişimsel işlemin uygulandığı aile sağlığı merkezlerinde çalışıyor olması nedeniyle iş kazası sıklıklarının yüksek olmadığı düşünülmektedir.

Çalışanın hasta / hasta yakını tarafından hakarete uğramasını iş kazası olarak değerlendiren ve on 12 ayda iş yerinde sözlü şiddete uğradığını belirten 52 sağlık çalışanı olmakla birlikte, bu kişilerin yalnızca 8’i $(\% 15,38)$ "Son 12 ayda iş kazasına uğradınız mı?” sorusuna "Evet" cevabını vermiştir. Bu durum, çalışmaya katılan sağlık çalışanları- 
nın şiddeti iş kazası olarak görmedikleri dolayısıyla başta işverenin yükümlülükleri olmak üzere yasanın kendilerine tanıdığı hakları yeterince bilmediklerini göstermektedir. Araştırmaya katılanların \%55,98'i son 12 ay içerisinde iş yerinde genel olarak şiddete maruz kaldığını belirtirken, sözel şiddete maruz kalma sıklığı \%55,43’tür. Fiziksel şiddete uğrama sıklığı ise \%1,09'dur. Sivas il merkezindeki sağlık çalışanlarında yürütülen bir çalışmada da son bir yıl içerisinde şiddete uğrama sıklığı \%49,79 iken, sözel şiddete maruz kalma sıklığı \%43,38'dir. ${ }^{8} 2017$ yılında Türkiye genelinde yapılan 12.944 sağlık çalışanının katılımı ile gerçekleşen bir çalışmada son 12 ay içerisinde iş yerinde şiddet görme sıklığı \%44,70 iken, çalışanların \%43,20'si sözel, \%6,80'i fiziksel şiddete maruz kaldığı saptanmıştır. ${ }^{9}$ Literatürdeki diğer çalışmalarda da sağlık personeline yönelik şiddetin büyük çoğunluğunun sözel şiddet olduğu gösterilmiştir.,10,11 $\mathrm{Bu}$ araştırmanın verileri ile literatürdeki diğer çalışmalar kıyaslandığında mevcut çalışmadaki katılımcıların fiziksel şiddete uğrama sıklığının daha düşük olduğu görülmektedir. Katılımcıların hangi branşlarda çalıştığı bilinmemekle birlikte, bu farkın, çalışmaya fiziksel şiddete uğrama sıklığı yüksek olan acil, psikiyatri gibi branşlardan katılımın düşük olmasından kaynaklanabileceği düşünülmektedir. Buna ek olarak, herhangi bir örnekleme yöntemi kullanılmadığından, çalışma grubundan elde edilen sonuçlar Sakarya ilini temsil etmemektedir.

Sağlık personeline yönelik şiddet, hasta ve/veya hasta yakınlarından kaynaklanabileceği gibi sağlık çalışanlarından ya da sağlık sisteminden kaynaklanan sorunlardan dolayı da ortaya çıkabilmektedir. Bu çalışmaya katılanların verdiği cevapların sadece $\% 2,01$ 'inde (7 cevap) sağlık personeline yönelik şiddetin en önemli nedeninin sağlık personeli kaynaklı olduğu belirtilirken, katılımcıların verdiği cevapların \%97,99'unda hasta/ hasta yakını veya sağlık sistemi ile alakalı nedenler olduğunu belirtmişlerdir.

Araştırmada çeşitli kısıtlılıklar mevcuttur. Tanımlayıcı tipte olduğundan araştırma sonuçlarının topluma genellenebilmesi mümkün olmamıştır. Katılımcıların çalış- tıkları bölüm ve meslekteki çalışma süreleri veri toplama sürecinde değerlendirmeye alınamadığından, bu verilerle ilgili karşılaştırma yapılamamıştır. Katılımcı sayısının fazla olmaması nedeniyle iş kazası ve sağlıkta şiddetle ilgili verilerde ileri analiz yapılamamıştır.

Sonuç olarak sağlık personeline yönelik şiddet tüm dünyada olduğu gibi ülkemiz için de önemli bir sorundur. Sağlık personeline yönelik şiddeti önlemede mevcut mekanizmaların yanı sıra iş sağlı̆̆ı ve güvenliği mevzuatının çalışanlara tanıdığı haklar ve işverenlere getirdiği yükümlülüklerin de dikkate alınması gerektiği kanaatindeyiz. Bu amaçla meslek örgütleri, sendikalar, dernekler sağlık çalışanlarını bilinçlendirebilir ve hukuki süreçlerin başlatılmasında destek olabilir. Aynı şekilde sağlık kurumu yöneticilerinin de mevcut iş sağlığı ve güvenliği mevzuatı dikkate alınarak, zor durumlara düşmemeleri için rehberliğe ihtiyaçları vardir.

Sağlıkta şiddet çok faktörlü bir sorundur. Ortaya çıkardığı olumsuz sonuçlar hiç ayrım gözetmeksizin toplumun tüm fertlerini etkilemektedir. Önyargılar ve karşılıklı suçlamaların sorunu derinleştirmekten öte bir etkisi yoktur. Bugün yaşadığımız durum maalesef tam da böyledir. Bu karmaşık soruna çözüm ararken sosyoloji, tıbbi antropoloji ve epidemiyoloji gibi bilim alanlarından yardım alınması ve özellikle nitel araştırmalar ile ilk adımların atılması gerektiğine inanıyoruz. 
Sakarya Tip Dergisi 2019;9(4):612-618

KiBAR ve Ark., Sağlık Çalışanlarının Sağlıkta Şiddet ile İlgili Görüșleri

\section{Kaynaklar}

1. Abdellah RF, Salama KM. Prevalence and risk factors of workplace violence against health care workers in emergency department in Ismailia. Egypt Pan Afr Med J. 2017; 26: 21.

2. Arnetz J, Hamblin L, Russell J; Upfal M, Luborsky M, Janisse J, Essenmacher L. Preventing Patient-to-Worker Violence in Hospitals: Outcome of a Randomized Controlled Intervention. Journal of Occupational and Environmental Medicine 2017;59(1):18-27.

3. Violence at work in the European Union-2009 http://www.ilo.org/safework/info/publications/WCMS_108536/lang--en/index.htm (Erişim tarihi: 06.08.2019)

4. https://www.who.int/violence_injury_prevention/violence/workplace/en/ (Erișim tarihi: 06.08.2019)

5. Keser Özcan N, Bilgin H. Türkiye’de Săgltk Çalışanlarına Yönelik Șiddet: Sistematik Derleme. Turkiye Klinikleri J Med Sci 2011;31(6):1442-56

6. https://www.ilo.org/stat/Publications/WCMS_173153/lang--en/index.htm (Erişim tarihi: 06.08.2019)

7. Guidelines for Preventing Workplace Violence for Healthcare and Social Service Workers-2016 https://www.osha.gov/Publications/osha3148.pdf(Erişim Tarihi: 06.09.2019)

8. Sağllkta Ulusal Renkli Kodlar https://dosyamerkez.saglik.gov.tr/Eklenti/6409,ulusal-renk-kodlarpdf.pdf?o (Erișim Tarihi: 06.09.2019)

9. Sağllk Bakanlı̆̆ ve Bă̆lı Kuruluşlarının Teşkilat ve Görevleri Hakkında Kanun Hükmünde Kararname-2011 http://www.resmigazete.gov.tr/eskiler/2011/11/20111102m1-3.htm (Erişim Tarihi: 06.09.2019)

10. Sağlık Bakanlı̆̆ı Personeline Karşı İșlenen Suçlar Nedeniyle Yapılacak Hukuki Yardlmin Usul ve Esasları Hakkında Yönetmelik-2012 http://www.resmigazete.gov.tr/eskiler/2012/04/20120428-3.htm (Erişim Tarihi: 06.09.2019)

11. Hukuki Yardim ve Beyaz Kod Uygulamast Genelgesi-2011 https://dosyasb.saglik.gov.tr/Eklenti/439,hybupdf.pdf?0 (Erişim Tarihi: 06.09.2019)
12. İș Sağhlğı Ve Güvenliği Kanunu-2012 http://www.resmigazete.gov.tr/eskiler/2012/06/20120630-1.htm (Erişim tarihi: 06.08.2019)

13. Sosyal Sigortalar Ve Genel Sağlk Sigortası Kanunu-2006 http://www.resmigazete.gov.tr/ eskiler/2006/06/20060616-1.htm (Erişim Tarihi: 06.09.2019)

14. Akça N, Yılmaz A, Ișıł O. Sağlık Çalışanlarına Uygulanan Șiddet: Özel Bir Tip Merkezi Örneği. Ankara Sağlık Hizmetleri Dergisi 2014;13(1):1-12

15. Türkmenoğlu B, Sümer HE. Sivas İl Merkezi Sağlı Çalışanlarında Şiddete Maruziyet Sıklğ. Ankara Med J, 2017;(4):216-25.

16. Pinar T, Acikel C, Pinar G, Karabulut E, Saygun M, Bariskin E et al. Workplace Violence in the Health Sector in Turkey: A National Study. J Interpers Violence. 2017 Aug;32(15):23452365 .

17. Uçak A, Kiper S, Karabekir H. Sağlık Çalışanlarının Karşslaştıkları İs Kazaları ve Eğitimin İs Kazaların Azaltma Durumuna Etkisi. Bozok Tip Derg. 2011;3:7-15

18. Durduran Y, Demir LS, Uyar M, Demirtaș A, Erdoğan A, Arbağ H. Sağlık Çalışanlarında İș Kazast ve Ramak Kala Olaylara Retrospektif Bakış. Kocatepe Medical Journal 2019;20:131136

19. Kahriman I, Polat S, Ede G, Kaptan D. Injury Experiences and Precautions Taken by Nurses Working in Pediatric Wards Towards Penetrative/ Incisive Tools. Int J CaringSci 2016;9(2):569-578

20. Bahar A, Șahin S, Akkaya Z, Alkayiş M. Acil Serviste Çalışan Hemşirelerin Şiddete Maruz Kalma Durumu ve Iș Doyumuna Etkili Olan Faktörlerin İncelenmesi. Psikiyatri Hemșireliği Dergisi 2015;6(2):57-64.

21. Turhan Ö, Ahmed F, Aslan D, Erişgen G, Çakır B, Şengelen M, Yildız AN. Önlenebilir Bir Sorun: Hekime Yönelik Şiddet. Ankara: Türk Tabipler Birlĭgi Yayınlarl; 2014. s:10, 16 